\title{
A specific building simulation tool for the design and evaluation of innovative fenestration systems and their control
}

\author{
Bruno Bueno ${ }^{1}$, Abel Sepúlveda ${ }^{1}$ \\ ${ }^{1}$ Fraunhofer Institute for Solar Energy Systems ISE, Freiburg, Germany
}

\begin{abstract}
Building facades regulate important building functions, such as daylighting provision, glare protection and solar heat gain management. Switchable facade elements in combination with a control strategy must be considered in order to dynamically balance these functions, which are of varying relevance, depending on the time of day and season. This paper presents an overview of the Fener tool, which was specifically developed for the design and evaluation of innovative fenestration systems and their control. The Fener tool is a building simulation program that couples daylighting and thermal calculations on a time-step basis, including thermal inertia calculations. This makes the tool particularly useful to assess innovative control strategies that depend at the same time on thermal and daylighting variables. The tool can calculate the impact of a fenestration system on the daylight availability, glare risk, thermal comfort and energy demand of a room. In this study, the Fener tool is used to develop control strategies for an innovative angle-selective and switchable textile technology. The control strategies are specific to the use of the building. Two different building uses are analysed: an office and a hospital ward.
\end{abstract}

\section{Introduction}

The design and evaluation of facade technologies is a specific problem within building performance simulation. The building facade provides many functions to building occupants, such as daylight provision, glare protection, solar heat gain management, visual contact with the outside and privacy (Kuhn, 2017), which are crucial for the building to be comfortable and energy efficient. The problem is that some of these functions are rather difficult to represent numerically. The reason for this difficulty is twofold. On the one hand, these functions respond to complex optical and thermal processes involving semi-transparent fenestration materials and components. On the other hand, many of these functions depend on a subjective perception of comfort and well-being.
In addition, some of these functions act in opposing directions. Therefore, the design of fenestration technologies and control strategies can only aim to balance the different functions without maximizing all of them simultaneously. Goal-oriented design of a building facade requires the dynamic quantification of these functions, taking into account the use of the building, its orientation and the climatic conditions of the location. Given the difficulties of quantifying some these functions in practice, the decision about a fenestration system and a control strategy for a certain building application is often made based on qualitative assessment of some of these functions. The risk of miscalculating or ignoring some of the crucial functions of building facades is that initially planned functions may not play a role in practice, if the day-by-day use of the fenestration system is completely different to the plan (Kuhn et al., 2001). The consequences can vary from sub-optimal performance of the facade to the replacement of the whole facade system if, for example, a severe glare problem is detected during the operation of the building.

Specific building simulation tools have some advantages over generally applicable building simulation platforms such as Open Studio (www.openstudio.net), Diva plug-in for Rhino (diva4rhino.com) and IDA-ICE (www.equa.se). The use of specific simulation tools for a given problem in building performance evaluation requires background knowledge, which is crucial to being able to interpret the results of the simulation. The scope of these specific tools is also more closely related to the assumptions made to develop them. The number of input parameters is also smaller and thus the accumulated uncertainty of the simulation results is reduced (Calleja-Rodriguez et al., 2013).

A fenestration system has a first-order impact on one room and a secondary effect at the building level through the HVAC system. Therefore, a room is a suitable domain for a simulation tool that aims to evaluate facade technologies. The tool must also be able to represent the complex thermal and optical processes that occur in fenestration systems, and 
implement state-of-the-art models for visual and thermal comfort. An essential feature of specific simulation tools is also their ability to simulate advanced control strategies, because these are crucial to correctly balancing the different building functions provided by fenestration systems.

EnergyPlus (Crawley et al., 2001), the most widely used building simulation tool, implements a daylighting module based on the radiosity method (Winkelmann, 1983). Although this method is accurate enough in many applications, it has been largely overtaken by the daylight coefficient method (Reinhart and Herkel, 2000) and the three-phase method (Ward et al., 2011), the latter being more appropriate for the simulation of control strategies for fenestration systems. The possibility to couple EnergyPlus with daylighting simulations (either three-phase method or daylight coefficient) is offered by Open Studio and Diva plug-in for Rhino. These tools couple the output of an annual daylight simulation with a thermal model of the building, which is sufficient to simulate control strategies that depend only on optical variables, such as outdoor irradiance, daylighting and glare indexes. However, for control strategies that additionally depend on thermal variables such as the indoor air temperature, a time-step coupling between the thermal problem and the daylighting/optical problem is required. One tool that offers this time-step coupling is DALEC (Werner et al., 2017). This tool offers a very high computational speed at the price of restricting the number of available building configurations to be simulated. The thermal model of the fenestration system is based on a layer-by-layer approach (EN 13790), which has important limitations as explained later on in the text.

This paper gives an overview of Fener, a tool that has been specifically developed for the design and evaluation of fenestration systems and their control (Bueno et al., 2015, 2017). Fener is a building simulation engine based on the three-phase method (Ward et al., 2011) and a detailed energy balance of one room. It calculates simultaneously the heating and cooling energy demand of the room, thermal comfort metrics, daylighting metrics and daylight glare indexes. Outward visual contact and privacy can also be taken into account through the control strategy. The tool provides significant flexibility and accuracy in the definition of fenestration systems and is very powerful in testing innovative control strategies for them.

A case study is presented to illustrate one of the applications of the Fener tool. Advances in the fabrication of textiles have made it possible to design switchable, angle-selective textiles for building applications. The Fener tool is used in this study to develop suitable control strategies for one of these textile shading devices. The control strategies are

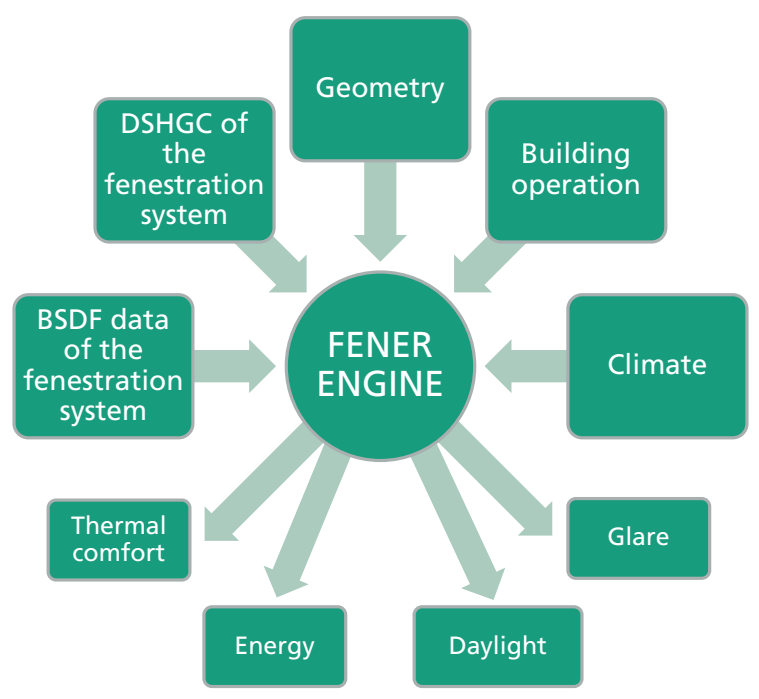

Figure 1: Diagram of the Fener tool.

specific to the use of the building, depending on a set of requirements for the facade functions. Two scenarios are considered: an office and a hospital ward. For this case study, control strategies with different levels of complexity are compared.

\section{The Fener tool}

A diagram of the Fener tool is shown in Fig. 1. In the following sections, the different Fener modules are described. The Fener tool has been evaluated against reference simulation engines, such as EnergyPlus and Radiance, and against measurements in a number of studies (Bueno et al., 2015, 2017; Katsifaraki et al., 2017).

\section{Daylighting module}

The Fener tool uses the three-phase method (Ward et al., 2011) for daylighting calculations. The threephase method applies a matrix formalism to link the radiance at the sky dome (including the sun) with predefined sensor points in the room. The model divides the light transport into three "phases": outdoor, indoor and transmission through the facade, each one of them represented by a matrix of daylight coefficients. This division makes the model particularly useful to simulate control strategies because only the transmission matrix may need to change at each timestep, whereas the outdoor and indoor matrices remain constant during the simulation. The method is also very computationally efficient and requires only one time-consuming task to generate the outdoor and indoor matrices through the Radiance program rcontrib. The dynamic simulation is then run entirely in a Python environment and consist of matrix multiplication calculations.

The three-phase method relies on Bi-directional Scattering Distribution functions that have a predefined resolution for the incoming and outgoing light directions (transmission matrix). Without a predefined resolution, the matrix formalism cannot be applied. 
Hemisphere of incoming light

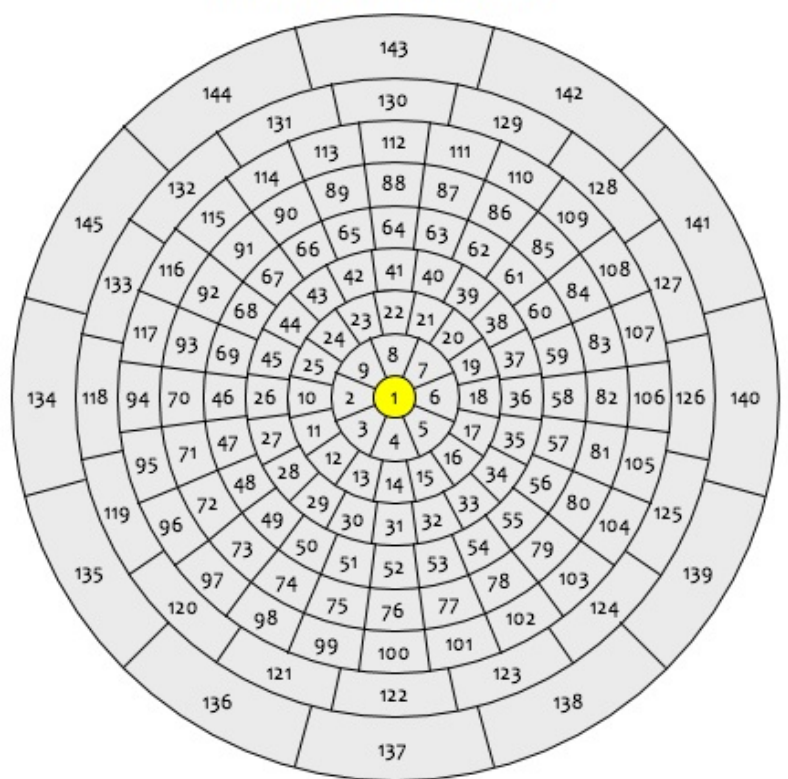

Figure 2: Incoming light directions according to the Klems' formalism.

An extensively used matrix format is known as the Klems format and consists of a matrix of 145 incoming light directions by 145 outgoing light directions (Fig. 2). The Fener tool implements the Klems matrix format although higher resolution formats could be implemented in the future.

The three-phase method is preferred to the five-phase method, because the former has been proven to perform sufficiently well for daylighting calculations (Lee et al., 2018). The five-phase method is an extension of the three-phase method that enhances the direct radiation calculation. The five-phase method requires, in addition to the Klems transmission matrix, a more advanced, tensor-tree BSDF format, which allows an adaptive resolution of light directions depending on the rate of change of light intensity in the BSDF. The tensor-tree BSDF can also be replaced by a geometrical model of the fenestration system. Both a tensor-tree and a geometrical model of a fenestration system including light-scattering or light-redirecting components are difficult to obtain.

The three-phase method is applied to calculate illuminance values at a user-specified grid of horizontal sensors, which are then used to analyse the daylighting conditions in the room. Metrics such as the Daylight Autonomy (Heschong et al., 2013) and the number of hours for which the workplane illuminance is above a threshold can be then calculated. The illuminance at a user-specified control sensor is passed to a lighting control algorithm in order to obtain the electric lighting demand.

\section{Glare module}

The Fener tool offers two options to quantify glare risk throughout a year:

- Vertical illuminance at eye level.
- The Enhanced Simplified DGP method (Wienold, 2009).

In both cases, the illuminance at a user-specified grid of vertical sensors is calculated by the three-phase method (see previous section for a description of the three-phase method). Each vertical sensor represents a view position and direction where glare risk will be assessed.

The Enhanced Simplified DGP method is based on the Daylight Glare Probability (DGP) index (Wienold and Christoffersen, 2006), a metric that can be calculated with the Radiance-based program evalglare. The DGP accounts for two possible sources of glare: 1) light saturation at eye level and 2 ) the effect of light contrast in the field of view produced by small and intense glare sources. For the Enhaced Simplified method, the evalglare program requires the vertical illuminance at eye level and a simplified luminance map of the field of view, which can be calculated with the Radiance program rtrace. This simplified image neglects the ambient bounces of light rays, i.e. it uses only the direct component of the light sources, but it has been shown to preserve the relevant information required to capture the contrast effect of the DGP method.

The calculation of the simplified image requires a tensor-tree BSDF or a geometrical model of the fenestration system, which adds substantial complexity to the model. The rendering process is also a timeconsuming task (it takes a few seconds for one image). This is still acceptable for dynamic calculations but makes Fener simulations slow (simulation of one year takes a few hours).

Alternatively, the vertical illuminance can be used as a glare metric. The calculation of vertical illuminances with the three-phase method is very computationally efficient (simulation of one year takes a few minutes). Vertical illuminance at eye level accounts only for the saturation effect of glare, neglecting the contrast effect. However, the method seems to perform well compared to the DGP except for dim light conditions where the solar disk is in the field of view without being completely blocked by a shading device (Konstantzos and Tzempelikos, 2017). It is then up to the modeller to decide whether the occurrence of such conditions during one year can affect the glare risk assessment of the shading device. In critical scenarios, the Enhanced Simplified Method must be used.

\section{Thermal module}

Fener also uses the three-phase method to calculate the transmitted solar radiation, as well as the fraction of it that is absorbed by each of the indoor surfaces of the room (Bueno et al., 2015). For this calculation, not only the luminance from the sky dome is required but also the radiance. Likewise, the BSDF of the fenestration system has to be provided for both 
the visible and the solar spectral ranges.

In addition to the optically transmitted solar radiation, fenestration systems absorb solar radiation and transmit it as heat to the indoor environment by convection and radiation. The ability of a fenestration system to prevent solar heat gains is represented by its Directional Solar Heat Gain Coefficient (DSHGC) or angle-dependent g-value, which is a measure of the total fraction of incident solar irradiance that is transmitted into the building through a fenestration system for different incoming directions. The DSHGC can be reliably measured with a solar calorimeter under stationary laboratory conditions (Kuhn, 2014).

The DSHGC of a fenestration system does not provide information about whether the absorbed solar irradiance will be transmitted to the indoor environment via convection or radiation. However, the convection/radiation split is crucial for the prediction of indoor thermal conditions. To calculate the surface temperature on the room-facing surface of the fenestration system and, therefore, the convection/radiation split, the Fener tool uses the Kuhn model (Kuhn et al., 2011) in the version presented by (Bueno et al., 2017). This model consists of replacing a real complex fenestration system by a virtual two-layer system with the same thermal and optical performance.

In this way, the Fener tool avoids the conventional layer-by-layer approach to represent the heat transfer through fenestration systems, making it generally applicable to a wide range of systems. The layer-bylayer approach, which is implemented for example in the ISO 15099 and the EN 13790 standards, relies on a number of assumptions that are not justified in the case of three-dimensional structures, air- permeable layers and deviations from ideal geometries, which are common features in commercial daylighting and solar-control systems.

The energy balance method is used in the Fener tool to calculate the thermal conditions in the room. An energy balance is solved at each indoor surface accounting for the convective heat exchange with the indoor air, the radiative heat exchange with other surfaces and with internal heat gains, and the conductive heat flux towards the interior of the surface. The tool applies conventional models to obtain the heat transfer coefficients at the surface (DOE, 2016). To model the transient conductive heat transfer through opaque elements (i.e. walls, ceiling and floor), the tool implements a conduction transfer functions method (Mitalas and Stephenson, 1967), which is computationally more efficient than the alternative finite differences method.

The tool solves a sensible and latent energy balance at the indoor air node to calculate its temperature and humidity. The cooling and heating energy demand is calculated as the amount of additional energy that has to be provided to the air node in order to keep the temperature between cooling and a heating set- points. The relative humidity of the air is used in the thermal comfort module in order to estimate the heat losses of the human body through the skin and respiration.

\section{Thermal comfort module}

Complex fenestration systems affect the thermal comfort of occupants in a room through various mechanisms:

- By increasing or decreasing the mean radiant temperature of a room if the indoor surface temperature of the facade system is different from other surface temperatures of the room.

- By increasing or decreasing the air temperature of the room by convection from the interior surface of the facade system.

- By direct transmitted solar radiation incident on the human body.

The thermal comfort module implemented in Fener is based on the ASHRAE 55 and the ISO 7730 standards. It uses a seven-point thermal scale, known as the predicted mean vote (PMV), to predict the mean value of votes by a large group of persons. It also calcuates the Predicted Percentage of Dissatisfied (PPD) index. The PMV and PPD methods are based on a heat balance at the skin of the human body.

The effect of the direct transmitted solar radiation on a human body can be calculated as an increment in the predicted mean vote, which is proportional to the directly transmitted solar radiation (Hodder and Parsons, 2007).

The perceived mean radiant temperature in a room depends on the occupant position in the room. Five different occupant positions are evaluated in the tool.

\section{Input parameters}

The Fener tool needs the following information as input parameters:

- Hourly weather data in epw format.

- The geometrical configuration of the room.

- Position and orientation of illuminance sensors in the room.

- Layer-by-layer thermal properties of opaque constructions.

- Occupation profiles.

- Internal heat gains, split into convective and radiative, latent and sensible components.

- Illuminance setpoint for electric lighting demand.

- Infiltration/ventilation measured in air changes per hour $(\mathrm{ACH})$

- Cooling and heating thermal setpoints for the calculation of building energy demand. 
- The geometrical configuration of outdoor obstructions.

Additionally, the tool requires the following data for every fenestration system to be simulated:

- U-value.

- Directional Solar Heat Gain Coefficients (DSHGC).

- Bi-directional Scattering Distribution Functions (BSDF) for the solar spectral range for irradiance calculations.

- BSDF for the visible spectral range for daylighting and visual comfort calculations.

\section{Case study}

In this section, the Fener tool is used to develop shading control algorithms for a new shading technology. Recent improvements in the fabrication of textiles make it possible to manufacture textiles with enhanced functionality for architectural applications. The German project TextilKFFS is developing switchable and angle-selective shading devices on the basis of a new textile structure. Within this project, control strategies for these new shading devices must also be developed in order to exploit their enhanced functionally.

This case study comprises two different scenarios, an office and a hospital ward. For each scenario, two control algorithms with different levels of complexity are compared. The goal is to understand the benefit of adding complexity to the control algorithms for the new shading technology.

The boundary conditions of the two scenarios are indicated in Table 1. For this case study, the office and hospital ward have the same geometrical configuration and boundary conditions, except for the occupation profile. While the office is occupied from $8 \mathrm{~h}$ to $18 \mathrm{~h}$, the hospital room is continuously occupied. The room has one external facade with two windows (Fig. 3). While the lower window primarily provides glare protection, view contact to the outside and solar heat gain management, the upper one is primarily responsible for daylighting. A grid of horizontal sensors is used to evaluate the daylighting conditions in the room. Likewise, vertical illuminance sensors are used to evaluate glare at eye level. A heat-mirror double glazing unit is used in combination with a switchable textile shading device. The textile shading device has two different modes of operation, unblocked and blocked, associated with a maximum normal-hemispherical transmittance of $30 \%$ and $22 \%$, respectively, as well as relatively low cut-off angles (Fig. 4).

A workflow for developing control algorithms for fenestration systems was proposed by (Bueno et al., 2018). According to this workflow, the first step is to determine the relevant functions of the fenestration system for each specific building application. In this
Table 1: Boundary conditions of the office and hospital ward considered in the case study.

\begin{tabular}{|l|l|}
\hline Building type & $\begin{array}{l}\text { Office } \\
\text { Hospital }\end{array}$ \\
\hline Location & Frankfurt \\
\hline Orientation & South \\
\hline Glazing ratio & $80 \%$ \\
\hline Room dimensions (LxDxH) & $4 \mathrm{~m} \times 5 \mathrm{~m} \times 3 \mathrm{~m}$ \\
\hline Occupation & $\begin{array}{l}\text { Office: } 8-18 \\
\text { (weekdays) } \\
\text { Hospital: } 24 \mathrm{~h}\end{array}$ \\
\hline Infiltration/ventilation & $0.6 \mathrm{ACH} / 0.2 \mathrm{ACH}$ \\
\hline Internal heat gains & $12 \mathrm{~W} \mathrm{~m}{ }^{-2}$ \\
\hline Cooling thermal setpoint & $26^{\circ} \mathrm{C} / 30^{\circ} \mathrm{C}$ \\
\hline Heating thermal setpoint & $21^{\circ} / 17^{\circ} \mathrm{C}$ \\
\hline
\end{tabular}

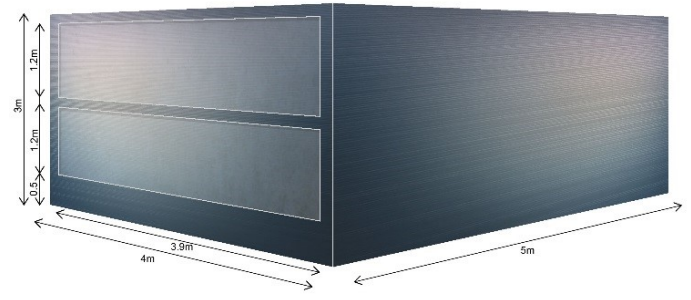

Figure 3: Sketch of the room under study.

case study, the most important function for the office scenario is determined to be glare protection, while daylighting and solar heat gain management are also to be included. On the other hand, for the hospital scenario, daylighting and visual contact to the outside have highest priority, while solar heat gain management and privacy during the night are also relevant functions.

For each of these functions, a control variable has to be defined. Additionally, a set of metrics is selected to evaluate the ability of the different control algorithms to fulfil each of the facade functions (Table 2). To calculate these metrics, extreme situations, such as the same room with opaque or completely transparent windows, have to be defined as upper limits for daylight autonomy, cooling and heating energy demand. As a result, the range for all of the selected metrics is between $0 \%$ and $100 \%$, with $100 \%$ being the best value for the given function.

The developed control algorithms together with the chosen thresholds for each of the controlling variables are described in Tables 3 and 4 for the office and hospital rooms, respectively.

In the office scenario, the lower window remains unshaded when the maximum vertical illuminance is lower than 2700 lux and the room air temperature is lower than $23^{\circ} \mathrm{C}$. The shading device is activated in the blocked mode when the maximum vertical illumi- 


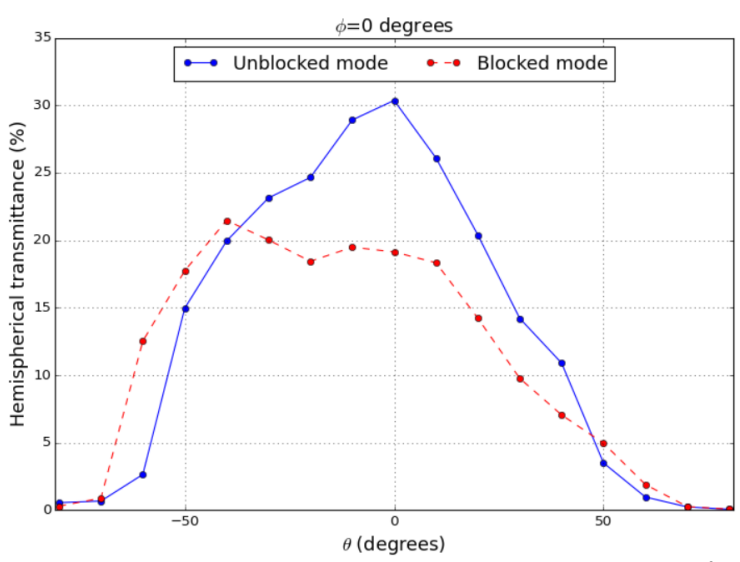

Figure 4: Direct hemispherical transmittance of the switchable shading device for its blocked and unblocked states. Optical profiles are plotted as a function of the polar angle $(\theta)$ for zero-azimuth angle $\left(\phi=0^{\circ}\right)$.

nance exceeds 3500 lux. The upper window is covered with the shading device in the unblocked mode when the average horizontal illuminance is higher than 2000 lux and the maximum vertical illuminance is lower than 2700 lux. When the latter is higher than 3500 lux, the shading device is activated in the blocked mode. When the office is vacant, the control algorithm operates in the energy-efficiency mode as a function of the indoor air temperature.

In the hospital scenario, the lower window is covered with the shading device in the unblocked mode when the room temperature is higher than $23^{\circ} \mathrm{C}$, whereas the shading device is retracted completely when the temperature is lower than $23^{\circ} \mathrm{C}$. The upper window is not covered by the shading device unless the average horizontal illuminance is higher than 200 lux and the interior room air temperature is higher than $23^{\circ} \mathrm{C}$ (unblocked mode). During the night, both windows are covered by the textile shading device in the blocked mode in order to give privacy to the patients. The advanced control algorithms for the office and the hospital ward that have just been described are compared with basic control algorithms, in which only the most important function is controlled (Tables 3 and 4).

The results of the comparison are shown in Table 5. It can be seen that for both the office and the hospital ward, the basic control strategy is able to maximize the metric that corresponds to the controlled function. The advanced algorithm, on the other hand, achieves better scores in all the other functions. For the office, the advanced control algorithm achieves similar glare protection to the basic control algorithm. However, the daylighting performance for the hospital ward with the advanced control algorithm is significantly poorer than that with the basic control. Nevertheless, both the advanced and the basic control algorithms achieve good performance of the rooms, with scores greater than $70 \%$ for all functions.
Table 2: Selected metrics to evaluate each of the facade functions in the case study. The transparent and opaque windows has the same thermal properties as the original window but $100 \%$ transmittance and 0\% transmittance, respectively.

\begin{tabular}{|l|l|l|}
\hline Function & $\begin{array}{l}\text { Control } \\
\text { variable }\end{array}$ & Metric \\
\hline $\begin{array}{l}\text { Daylight } \\
\text { provision }\end{array}$ & $\begin{array}{l}\text { Average } \\
\text { hori- } \\
\text { zontal } \\
\text { illumi- } \\
\text { nance }\end{array}$ & $\begin{array}{l}\text { = (Hours with average horizon- } \\
\text { tal illuminance }>\text { 400 lux }) /( \\
\text { Hours with average horizontal il- } \\
\text { luminance }>400 \text { lux for trans- } \\
\text { parent window) }\end{array}$ \\
\hline $\begin{array}{l}\text { Glare } \\
\text { protec- } \\
\text { tion }\end{array}$ & $\begin{array}{l}\text { Maximum } \\
\text { vertical } \\
\text { illumi- } \\
\text { nance }\end{array}$ & $\begin{array}{l}\text { illuminance }<\text { mith maximum vertical } \\
\text { number of daylight hours) }\end{array}$ \\
\hline $\begin{array}{l}\text { Solar } \\
\text { heat } \\
\text { gain } \\
\text { manage- } \\
\text { ment }\end{array}$ & $\begin{array}{l}\text { Indoor } \\
\text { air tem- } \\
\text { perature }\end{array}$ & $\begin{array}{l}\text { =1- (annual heating energy de- } \\
\text { mand)/(annual heating energy } \\
\text { demand for opaque window) }\end{array}$ \\
& & $\begin{array}{l}\text { 1- (annual cooling energy de- } \\
\text { mand)/(annual cooling energy } \\
\text { demand for transparent window) }\end{array}$ \\
\hline
\end{tabular}

\section{Conclusion}

Building simulation tools that are specifically designed to address certain building performance problems have advantages with respect to generally applicable building simulation programs. An example of such a tool is Fener, which was specifically developed to support the design and evaluation of fenestration technologies and their control. The tool can calculate the impact of a fenestration system on daylight availability, glare risk, thermal comfort and energy demand of a room.

Compared to state-of-the-art building energy models, such as EnergyPlus, Fener offers a time-step coupling between daylighting and thermal simulations. Fener also uses Bi-directional Scattering Distribution Functions (BSDF) and Directional Solar Heat Gain Coefficients (DSHGC) as input information in order to optically and thermally characterize fenestration systems. Alternative optical and heat transfer models for fenestration systems, which overcome some of the limitations of conventional models, are also implemented in the tool.

In this study, some of the features of the tool have been illustrated with a case study. The Fener tool is applied to develop and evaluate control strategies for a new shading device technology, based on switchable and angle-selective textiles. The control strategies are designed to meet a set of requirements concerning facade functions. Two scenarios are analyzed: an office, where glare protection and energy efficiency must be guaranteed, and a hospital ward, where views to 
Table 3: Control algorithm for the office. The table shows the conditions under occupation that must be fulfilled in order to have the window states indicated in the last two columns for the upper and lower partitions. In case of no occupation, the control algorithm is in the energy-efficiency mode, i.e. the shading device is retracted when the room temperature is below $23^{\circ} \mathrm{C}$. Otherwise the shading device is activated in the blocked mode. The different window states are the following: 0 - unshaded glazing unit, 1 - shading device activated in the unblocked mode and 2 - shading device activated in the blocked mode.

\begin{tabular}{|c|c|c|c|c|c|}
\hline \multicolumn{7}{|c|}{ Advanced algorithm } \\
\hline $\begin{array}{c}\text { Max. } \\
\text { vert. } \\
\text { illu. } \\
>2700 \\
\text { lux }\end{array}$ & $\begin{array}{c}\text { Max. } \\
\text { vert. } \\
\text { illu. } \\
>3500 \\
\text { lux }\end{array}$ & $\begin{array}{c}\text { Room } \\
\text { air } \\
\text { temp. } \\
>23^{\circ} \mathrm{C}\end{array}$ & $\begin{array}{c}\text { Mean } \\
\text { hor. } \\
\text { illu. } \\
>2000 \\
\text { lux }\end{array}$ & $\begin{array}{c}\text { Low. } \\
\text { win. } \\
\text { state }\end{array}$ & $\begin{array}{c}\text { Upp. } \\
\text { win. } \\
\text { state }\end{array}$ \\
\hline 0 & 0 & 0 & 0 & 0 & 0 \\
\hline 0 & 0 & 0 & 1 & 0 & 0 \\
\hline 0 & 0 & 1 & 0 & 1 & 0 \\
\hline 0 & 0 & 1 & 1 & 1 & 1 \\
\hline 1 & 0 & 0 & 0 & 1 & 0 \\
\hline 1 & 0 & 0 & 1 & 1 & 1 \\
\hline 1 & 0 & 1 & 0 & 1 & 0 \\
\hline 1 & 0 & 1 & 1 & 1 & 1 \\
\hline 1 & 1 & 0 & 0 & 2 & 0 \\
\hline 1 & 1 & 0 & 1 & 2 & 1 \\
\hline 1 & 1 & 1 & 0 & 2 & 1 \\
\hline 1 & 1 & 1 & 1 & 2 & 2 \\
\hline \multicolumn{7}{|c|}{ Basic algorithm } \\
\hline 0 & 0 & - & - & 0 & 0 \\
\hline 1 & 0 & - & - & 1 & 1 \\
\hline 1 & 1 & - & - & 2 & 2 \\
\hline 0 & 0 & - & - & 2 & 2 \\
\hline 1 & 0 & - & - & 2 & 2 \\
\hline 1 & 1 & - & - & 2 & 2 \\
\hline
\end{tabular}

the outside and daylighting must be optimized. Control strategies of different complexity are compared in terms of daylight provision, glare protection and solar heat gain management.

The study shows the benefits and limitations of adding complexity to the control algorithm in order to balance different facade functions.

An interface of the Fener tool is available through a web server https://fener-webport.ise.fraunhofer.de. The web-interface offers the user predefined building scenarios, for which the three-phase method matrices have already been calculated. With a few inputs in a user-friendly environment, new fenestration technologies can be quickly tested under different climate and building scenarios. The simulations of the webtool are run remotely on one of Fraunhofer ISE's servers.
Table 4: Control algorithm for the hospital ward. The table shows the conditions that must be fulfilled in order to have the window states indicated in the last two columns for the upper and lower partitions. The different window states are the following: 0 - unshaded glazing unit, 1 - shading device activated in the unblocked mode and 2 - shading device activated in the blocked mode.

\begin{tabular}{|c|c|c|c|c|}
\hline \multicolumn{5}{|c|}{ Advanced algorithm } \\
\hline $\begin{array}{c}\text { Mean } \\
\text { hor. } \\
\text { Illu. } \\
>200 \\
\text { lux }\end{array}$ & $\begin{array}{l}\text { Mean } \\
\text { hor. } \\
\text { Illu. } \\
>2000 \\
\text { lux }\end{array}$ & $\begin{array}{c}\text { Room } \\
\text { air } \\
\text { temp. } \\
>23^{\circ} \mathrm{C}\end{array}$ & $\begin{array}{c}\text { Lower } \\
\text { window } \\
\text { state }\end{array}$ & $\begin{array}{c}\text { Upper } \\
\text { window } \\
\text { state }\end{array}$ \\
\hline 0 & 0 & 0 & 0 & 0 \\
\hline 0 & 0 & 1 & 1 & 0 \\
\hline 1 & 0 & 0 & 0 & 0 \\
\hline 1 & 0 & 1 & 1 & 1 \\
\hline 1 & 1 & 0 & 0 & 0 \\
\hline 1 & 1 & 1 & 1 & 2 \\
\hline \multicolumn{5}{|c|}{ Basic algorithm } \\
\hline 0 & 0 & - & 0 & 0 \\
\hline 1 & 0 & - & 1 & 0 \\
\hline 1 & 1 & - & 1 & 1 \\
\hline
\end{tabular}

Table 5: Comparison of the annual performance of the shading device for two different control strategies (advanced and basic) for two different building uses (office and hospital).

\begin{tabular}{|l|l|l|l|l|}
\hline & \multicolumn{2}{|c|}{ Office } & \multicolumn{2}{c|}{ Hospital } \\
\hline Function & advanced & basic & advanced & basic \\
\hline $\begin{array}{l}\text { Daylight } \\
\text { provision }\end{array}$ & $92 \%$ & $87 \%$ & $84 \%$ & $95 \%$ \\
\hline $\begin{array}{l}\text { Glare } \\
\text { protec- } \\
\text { tion }\end{array}$ & $70 \%$ & $72 \%$ & - & - \\
\hline $\begin{array}{l}\text { Solar } \\
\text { heat gain } \\
\text { man- } \\
\text { agement } \\
\text { (Heating) } \\
\text { (Cooling) }\end{array}$ & $76 \%$ & $71 \%$ & $84 \%$ & $75 \%$ \\
\hline
\end{tabular}

\section{Acknowledgment}

This study was supported by the FraunhoferGesellschaft within its ICON Programme for International Cooperation and Networking (Project No.: 035-601764). This study was also partially supported by the German Federal Ministry of Economic Affairs and Energy by a resolution of the German parliament within the Textil-KFFS project (Project ID: 03ET1432A).

\section{References}

Bueno, B., J.-M. Cejudo-Lopez, and T. E. Kuhn (2017). A general method for the evaluation of the thermal impact of complex fenestration systems in 
building zones. Energy and Buildings 155, 43-53.

Bueno, B., J. M. Cejudo-López, A. Katsifaraki, and H. R. Wilson (2018). A systematic workflow for retrofitting office façades with large window-to-wall ratios based on automatic control and building simulations. Building and Environment 132, $104-113$.

Bueno, B., J. Wienold, A. Katsifaraki, and T. E. Kuhn (2015). Fener: A Radiance-based modelling approach to assess the thermal and daylighting performance of complex fenestration systems in office spaces. Energy and Buildings 94, $10-20$.

Calleja-Rodriguez, G., A. Carrillo-Andres, F. Dominguez-Munoz, J. Cejudo-Lopez, and Y. Zhang (2013). Uncertainties and sensitivity analysis in building energy simulation using macroparameters. Energy and Buildings 67, $79-$ 87.

Crawley, D. B., L. K. Lawrie, F. C. Winkelmann, W. Buhl, Y. Huang, C. O. Pedersen, R. K. Strand, R. J. Liesen, D. E. Fisher, M. J. Witte, and J. Glazer (2001). EnergyPlus: creating a newgeneration building energy simulation program. Energy and Buildings 33(4), 319 - 331.

DOE (2016). Energyplus Engineering Reference. EnergyPlusTM Documentation, v8.4.0 (accessed 2015.12.24).

Illuminating Engineering Society (2013). IES Spatial Daylight Autonomy (sDA) and Annual Sunlight Exposure (ASE).

Hodder, S. G. and K. Parsons (2007, Jan). The effects of solar radiation on thermal comfort. International Journal of Biometeorology 51(3), 233-250.

Katsifaraki, A., B. Bueno, and T. E. Kuhn (2017). A daylight optimized simulation-based shading controller for venetian blinds. Building and Environment 126(Supplement C), 207 - 220.

Konstantzos, I. and A. Tzempelikos (2017). Daylight glare evaluation with the sun in the field of view through window shades. Building and Environment 113(Supplement C), 65 - 77. Advances in daylighting and visual comfort research.

Kuhn, T. E. (2014). Calorimetric determination of the solar heat gain coefficient $\mathrm{g}$ with steadystate laboratory measurements. Energy and Buildings $84(0), 388-402$.

Kuhn, T. E. (2017). State of the art of advanced solar control devices for buildings. Solar Energy 154 (Supplement C), 112 - 133. Solar Thermal Heating and Cooling.
Kuhn, T. E., C. Buehler, and W. J. Platzer (2001). Evaluation of overheating protection with sunshading systems. Solar Energy 69, Supplement $6(0), 59-74$.

Kuhn, T. E., S. Herkel, F. Frontini, P. Strachan, and G. Kokogiannakis (2011). Solar control: A general method for modelling of solar gains through complex facades in building simulation programs. Energy and Buildings 43(1), $19-27$.

Lee, E. S., D. Geisler-Moroder, and G. Ward (2018). Modeling the direct sun component in buildings using matrix algebraic approaches: Methods and validation. Solar Energy 160, 380 - 395.

Mitalas, G. and D. Stephenson (1967). Room thermal response factors. ASHRAE Transactions 73, Part I.

Reinhart, C. F. and S. Herkel (2000). The simulation of annual daylight illuminance distributions a state-of-the-art comparison of six radiance-based methods. Energy and Buildings 32(2), $167-187$.

Ward, G., R. Mistrick, E. Lee, A. McNeil, and J. Jonsson (2011). Simulating the daylight performance of complex fenestration systems using bidirectional scattering distribution functions within Radiance. Journal of the Illuminating Engineering Society of North America 7 (4), 1-19.

Werner, M., D. Geisler-Moroder, B. Junghans, O. Ebert, and W. Feist (2017). Dalec - a novel web tool for integrated day- and artificial light and energy calculation. Journal of Building Performance Simulation 10(3), 344-363.

Wienold, J. (2009). Dynamic daylight glare evaluation. In In Preceedings of the Eleventh International IBPSA Conference, Glasgow, Scotland, July 27-30.

Wienold, J. and J. Christoffersen (2006). Evaluation methods and development of a new glare prediction model for daylight environments with the use of ccd cameras. Energy and Buildings 38(7), 743 - 757. Special Issue on Daylighting Buildings.

Winkelmann (1983). Daylighting Calculation in DOE-2. Lawrence Berkeley Laboratory report no. $L B L-11353$. 